\title{
Caracterização morfométrica, germinação e conservação de sementes de Caesalpinia pulcherrima (L.) SW. (Fabaceae: Caesalpinioidea)
}

\section{Morphometric characterization, germination and conservation of Caesalpinia pulcherrima (L) SW. (Fabaceae: Caesalpinioidea) seeds}

\author{
João Correia de Araújo Neto ${ }^{1 *}$; Celene de Albuquerque Camara ${ }^{2}$; \\ Vilma Marques Ferreira'; Bruno França da Trindade Lessa ${ }^{3}$; \\ Yolanda de Melo Oliveira ${ }^{4}$
}

\begin{abstract}
Resumo
O objetivo foi caracterizar a morfometria de frutos e sementes, identificar o melhor tratamento de superação de dormência, a melhor temperatura de germinação e avaliar o potencial de armazenamento de sementes de Caesalpinia pulcherrima, uma espécie arbóreo-arbustiva, utilizada como cerca viva, quebra vento e de amplo uso medicinal e paisagístico. Para a caracterização morfométrica, determinouse o comprimento, espessura, largura, massa de 1000 sementes, número de sementes por fruto, coloração, formato e localização do hilo e da micrópila, tipo de embrião, sua localização e tipo de germinação. A qualidade fisiológica das sementes foi avaliada em função de diferentes tratamentos de superação de dormência, temperaturas e condições de armazenamento. Os ensaios foram instalados sob delineamento inteiramente casualizado, com quatro repetições de 25 sementes. O fruto é do tipo legume, deiscente, polispérmico, contendo em média sete sementes, que apresentam formato oblongo-ovalado, embrião axial linear, com 9,6 $\mathrm{mm}$ de comprimento, 7,3 $\mathrm{mm}$ de largura por 3,3 $\mathrm{mm}$ de espessura. A escarificação mecânica das sementes em lado oposto à micrópila e a temperatura de $30^{\circ} \mathrm{C}$ constituíram no melhor tratamento germinativo. A qualidade fisiológica das sementes foi mantida por 270 dias, quando armazenadas com grau de umidade de 7\%, independente da embalagem e condições de armazenamento. Palavras-chave: Maravilha, morfologia, dormência, armazenamento
\end{abstract}

\begin{abstract}
The work had as objective to do a morphometric characterization of the fruits and seeds, to identify the best treatments to overcome dormancy, identify the best temperature for germination and also evaluate adequate conditions for storing the seeds of Caesalpinia pulcherrima (L.), which is a specie used for live fences, windbreakers, medicinal applications and urban landscaping. It was determined the biometrics measurements (length, width end thickness) and embryo type, weight of 1000 seeds, number of seeds per fruit, color, shape and micropyle and hlium position. It was evaluated the effect of different treatments to dormancy overcome, temperatures of germination and storing conditions. The
\end{abstract}

\footnotetext{
${ }^{1}$ Profs. Drs., Universidade Federal de Alagoas, UFAL, Centro de Ciências Agrárias, Maceió, AL. E-mail: jcanetto2@hotmail.com; vilmaferreira@ceca.ufal.br

${ }^{2}$ Bióloga, M.e em Agronomia, Produção Vegetal, UFAL/CECA, Maceió, AL. E-mail: celenec1@hotmail.com.

${ }^{3}$ Eng $^{\circ}$ Agr $^{\circ}$, Discente do Curso de Doutorado do PPG em Fitotecnia, Universidade Federal do Ceará, UFC, Fortaleza, CE. E-mail: brunoftl@yahoo.com.br

${ }^{4}$ EngaAgra $^{\mathrm{a}}$,UFAL/CECA, Maceió, AL. E-mail: yolanda.olivermelo@hotmail.com

* Autor para correspondência
} 
experimental procedures used were completely randomized with four repetitions of 25 seeds. The fruit of C. pulcherrima is a type of legume, dehiscent, polyspermic, with an average of 7 seeds per unit, which have an oblong-oval format, axial embryo, with $9.6 \mathrm{~mm}$ of length, $7.3 \mathrm{~mm}$ of width and 3.3 $\mathrm{mm}$ of thickness. The mechanical scarification of the seeds on the opposite side of the micropyle and temperature of $30^{\circ} \mathrm{C}$ provided the best results for germination. The physiological quality of the seeds was maintained for 270 days when the seeds were stored with $7 \%$ of moisture content independent of the package and storing conditions.

Key words: Guacamaya, morphology, dormancy, storage

\section{Introdução}

Popularmente conhecida como maravilha, flamboyanzinho e flor-do-paraíso a Caesalpinia pulcherrima (L.) Sw. (Fabaceae: Caesalpinioidea), é um arbusto lenhoso, originária da América Central, ereta, medindo de 3 a 4 metros de altura (LORENZI; SOUZA, 2008). A espécie tolera bem o calor e a estiagem (GILMAN; WATSON, 2003), podendo ser utilizada como cerca viva e quebraventos, bem como na arborização de cidades, em virtude do baixo porte e diversidade de suas inflorescências (OLIVEIRA et al., 2010). Apresenta ainda valor medicinal, pelo uso de suas partes no tratamento febres, infecções, úlceras bucais, feridas e irritações nos olhos (GILMAN; WATSON, 2003). Com todo esse potencial, poucos são os estudos envolvendo as características morfométricas de frutos e sementes, ou de informações que possam ser utilizadas em testes de germinação e vigor, bem como para planejar e garantir a conservação do potencial fisiológico das mesmas.

O conhecimento da biomorfologia, da germinação, do crescimento e estabelecimento de plantas é imprescindível para compreender o ciclo biológico e os processos de estabelecimento das espécies em seu habitat (CAMARA et al., 2008). É de grande importância para auxiliar na identificação botânica das espécies, contribuir para os estudos dos mecanismos de dispersão, sucessão e regeneração natural, assim como para fins filogenéticos e ecológicos (BASKIN; BASKIN, 1998; PEREZ, 2004).

A caracterização biomorfológica também permite identificar tratamentos pré-germinativos que possam ser utilizados para promover a germinação quando esta é baixa ou desuniforme. Isto pode ser observado em sementes de leguminosas tropicais, para as quais o tegumento impermeável à água é o tipo de dormência física mais comum (ROLSTON, 1978).

Como a produção de sementes é limitada temporalmente, estudos referentes ao seu potencial de armazenamento, visando posterior produção de mudas, são de fundamental importância, pois quando estocadas por determinados períodos e condições, podem perder sua capacidade germinativa (OLIVEIRA; SCHLEDER; FAVEIRO, 2006).

Diante da grande diversidade de espécies, há lacunas na literatura no que concerne à metodologia para testes germinativos, bem como para o estabelecimento de condições adequadas para o armazenamento de sementes de $C$. pulcherrima.

As sementes, de modo geral, são separadas em dois grupos, de acordo com a classificação proposta por Roberts (1973): no primeiro estão às chamadas ortodoxas que podem ser secas a baixos níveis de umidade (em torno de 5\%) e armazenadas em temperaturas baixas, o que possibilita a manutenção da sua viabilidade por um longo período. No segundo grupo têm-se as sementes recalcitrantes, que não toleram estas condições, portanto, apresentam dificuldades de armazenamento. Entretanto, um terceiro grupo foi identificado por Ellis, Hong e Roberts (1990) por apresentar respostas de armazenamento intermediário entre ortodoxo e recalcitrante. Nestes casos, as sementes toleram a desidratação somente até o teor de água entre $7 \%$ e 
$10 \%$ e não toleram temperaturas baixas por tempo prolongado (HONG; ELLIS, 1996).

Diante dessa diversidade, o primeiro passo para se estabelecer o armazenamento seguro das sementes é conhecer a tolerância das mesmas à dessecação, como observado, por exemplo, para sementes de Caesalpinia echinata Lam. (Caesalpinioideae), cuja conservação da qualidade fisiológica foi favorecida pela secagem das sementes associada à embalagem permeável (BARBEDO; BILIA; RIBEIRO, 2002), ao passo que em sementes de Cynometria bauhinifolia Benthan (Fabaceae) a conservação da qualidade fisiológica inicial é possível em sementes com alto grau de umidade (NAZARIO; FERREIRA; REBOUÇAS, 2008).

Além da umidade, a conservação da qualidade fisiológica das sementes está também relacionada ao tipo de embalagem utilizada, conforme a maior ou menor facilidade que a mesma apresenta para as trocas de vapor d'água entre as sementes e a atmosfera do ambiente em que estão armazenadas (MARCOS FILHO, 2005). Tais resultados podem ser verificados em sementes de Calliandra foliolosa Benth. (Fabaceae) onde a melhor conservação foi obtida quando estas foram acondicionadas em sacos de plástico e armazenadas em câmara fria (CALIL et al., 2007) e em embalagem de polietileno ou de papel para sementes de Sclerolobium paniculatum Vogel, Caesalpinioideae (ALVINO et al., 2007).

Diante da falta de informações a respeito das características biométricas e/ou ecofisiológicas das sementes de $C$. pulcherrima, objetivou-se caracterizar a morfometria de frutos e sementes, avaliar tratamentos de superação de dormência e temperaturas de germinação, além de avaliar diferentes condições de armazenamento das sementes dessa espécie.

\section{Material e Métodos}

O trabalho foi conduzido no Laboratório de Análise de Sementes pertencente ao Centro de
Ciências Agrárias (CECA), Campus Delza Gitaí, da Universidade Federal de Alagoas (UFAL), situado a 9'28'01'S, 35'49'32'W e $141 \mathrm{~m}$ de altitude. As sementes de $C$. pulcherrima foram extraídas de frutos maduros, colhidos com auxílio de tesoura de poda alta, de nove plantas localizadas nos municípios de Maceió e Rio Largo, estado de Alagoas. Nestes municípios predominam os solos do tipo Latossolo Amarelo e Argissolo Amarelo (JACOMINE et al., 1975) e o clima é do tipo As, tropical chuvoso com verões secos, segundo a classificação de Köppen.

Após a colheita, determinou-se o grau de umidade inicial das sementes utilizando estufa regulada a $105^{\circ} \mathrm{C} \pm 3^{\circ} \mathrm{C}$, conforme prescrição das Regras para Análise de Sementes (BRASIL, 2009), em duas amostras de 25 sementes.

Para realização da biometria, foram utilizadas oito repetições de 100 frutos e sementes, determinandose o comprimento, largura e espessura. Também foi determinada a massa de 1000 sementes (BRASIL, 2009). O número médio de sementes por fruto foi determinado, utilizando uma amostra de noventa frutos maduros. Para cada variável foram calculados a média, moda, mediana, desvio-padrão, coeficiente de variação, amplitude total e frequência relativa (LABOURIAU; VALADARES, 1976).

A caracterização morfológica das sementes foi realizada utilizando 25 sementes, as quais foram imersas em água destilada por 24 horas possibilitando os cortes longitudinal e transversal, sendo as estruturas observadas em estéreomicroscópio óptico (CÓRNER, 1976). Para tanto, foram analisadas a coloração, formato, localização do hilo, da micrópila, presença e tipo de material de reserva, tipo de embrião, sua localização e tipo de germinação.

Para avaliação da qualidade fisiológica inicial, as sementes foram submetidas a duas temperaturas de incubação $\left(25^{\circ} \mathrm{C}\right.$ e $\left.30^{\circ} \mathrm{C}\right)$ e três tratamentos pré-germinativos (sementes intactas, sementes escarificadas mecanicamente com lixa de n. 40 em lado oposto à micrópila e sementes imersas 
em água destilada por 24 horas), sendo semeadas em caixas plásticas do tipo gerbox transparentes contendo como substrato papel de filtro umedecido com volume de água de cerca de 2,5 vezes a massa inicial (BRASIL, 2009). Posteriormente, utilizando o melhor tratamento pré-germinativo, as sementes foram incubadas nas temperaturas constantes de $15,25,30,35,40$ e $45^{\circ} \mathrm{C}$, com fotoperíodo de oito horas, conforme utilizado para sementes das Fabáceas Peltophorum dubium (Spreng.) Taub. (OLIVEIRA; DAVIDE; CARVALHO, 2008), Bauhinia forficata Link e B. variegata L. (LOPES; BARBOSA; CAPUCHO, 2007). A contagem das sementes germinadas foi feita diariamente, durante 20 dias, até a estabilização da germinação.

Numa segunda etapa, a germinação foi avaliada em sementes contendo diferentes graus de umidade, os quais foram obtidos em estufa com ventilação forçada sob temperatura de $40^{\circ} \mathrm{C}$ pelos períodos de zero a 168 horas em intervalo de 24 horas. Transcorrida esta etapa, as sementes contendo grau de umidade de $7 \%$ foram acondicionadas em embalagens compostas por uma e/ou três folhas de papel tipo "Kraft" e frascos de vidro hermeticamente fechados e armazenadas em ambiente normal sem controle de temperatura e umidade relativa e em câmara seca regulada a temperatura de $23^{\circ} \mathrm{C}$ e $45 \%$ de umidade relativa por um período de nove meses, sendo a avaliação da germinação feita com zero, um, três e nove meses de armazenamento.

A qualidade fisiológica das sementes foi avaliada pela porcentagem $(\mathrm{G} \%)$ e velocidade de germinação (IVG), sendo consideradas germinadas as sementes que apresentaram raiz primária com comprimento $\geq 2 \mathrm{~mm}$ (GIACHINI et al., 2010). Durante o processo de secagem, foram retiradas amostras para a determinação da condutividade elétrica do exudato das sementes. Para tanto, 25 sementes foram imersas em $75 \mathrm{~mL}$ de água deionizada por 24 horas a $25^{\circ} \mathrm{C}$. Em seguida, fez-se a leitura da condutividade elétrica da solução de embebição utilizando um condutivímetro digital, sendo os resultados expressos em $\mu$ mhos $\mathrm{cm}^{-1} \mathrm{~g}^{-1}$

Os dados de G\% foram previamente transformados em arcsen $\sqrt{ } \mathrm{x} / 100 \mathrm{e}$, juntamente com dados de IVG, submetidos à análise de variância (teste F) e para comparação da G\% e IVG em função dos tratamentos pré-germinativos em interação com duas temperaturas e em função do período de secagem foi aplicado o teste de Tukey ao nível de 5\% de probabilidade de erro. Para análise da germinação e IVG em função de temperaturas crescentes e do tempo de armazenamento utilizouse regressão polinomial (BANZATTO; KRONKA, 1992).

\section{Resultados e Discussão}

O fruto de Caesalpinia pulcherrima é um legume deiscente, glabro, de coloração marrom escuro quando maturo, polispérmico, cuja deiscência dá-se no sentido longitudinal (Figura 1), com aberturas nas suturas ventral e dorsal, causando a separação das valvas, que por sua vez se mantém unidas na base do fruto. Tais valvas, quando abertas, podem apresentar-se torcidas em mais de uma volta. Essa torção faz com que as sementes sejam lançadas a certa distância da planta mãe, caracterizando-se como fruto autocórico com dispersão balística. 
Figura 1. Aspecto externo e interno de frutos de Caesalpinia pulcherrima (L.) Sw.

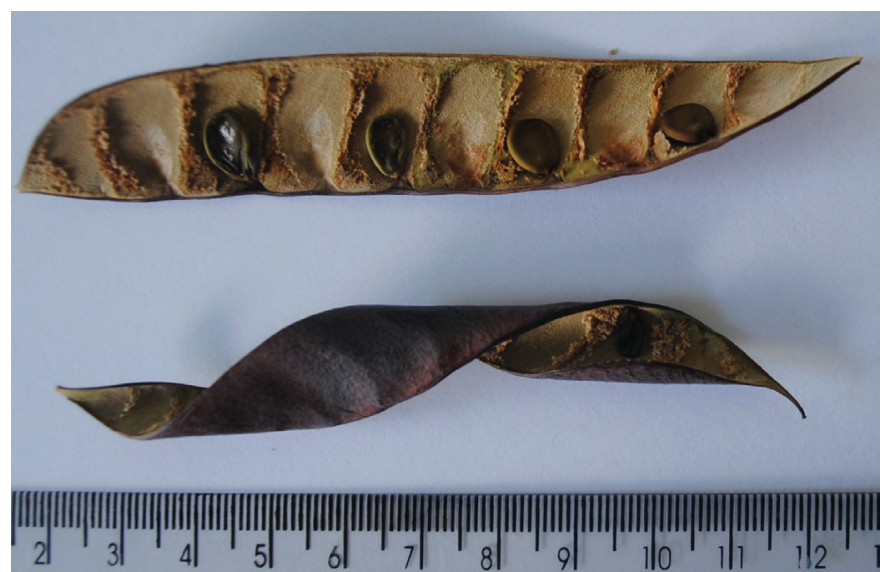

Fonte: Elaboração dos autores.

Os frutos maduros apresentam variação comprimento e largura dos frutos e resposta de comprimento, largura e espessura (Tabela simétrica $\left(\mathrm{m}_{0}=\mathrm{md}=\mathrm{m}\right)$ para a espessura dos 1), com deslocamento das curvas para a mesmos (Figura 2 E). Há também ampla variação esquerda do gráfico (Figura $2 \mathrm{~A}, \mathrm{C}$ ), indicando no número de sementes por fruto (Tabela1), resposta assimétrica negativa $\left(\mathrm{m}_{0}>\mathrm{md}>\mathrm{m}\right)$ para sendo encontradas de 2 a 15 sementes.

Tabela 1. Estatística descritiva do comprimento, largura e espessura de frutos e sementes e número de sementes por fruto de Caesalpinia pulcherrima (L.) Sw.

\begin{tabular}{lccccccc}
\hline \multirow{2}{*}{$\begin{array}{l}\text { Medidas } \\
\text { estatísticas }\end{array}$} & \multicolumn{2}{c}{ Comprimento $(\mathrm{mm})$} & \multicolumn{2}{c}{ Largura $(\mathrm{mm})$} & \multicolumn{2}{c}{ Espessura $(\mathrm{mm})$} & $\begin{array}{c}\mathrm{N}^{\circ} \text { de sementes/ } \\
\text { fruto }\end{array}$ \\
\cline { 2 - 7 } & fruto & semente & fruto & semente & Fruto & semente & \\
\hline Média & 10,1 & 9,6 & 19,0 & 7,2 & 7,0 & 3,2 & 7,0 \\
Moda & 10,8 & 9,2 & 20,0 & 7,2 & 7,0 & 3,2 & 9,0 \\
Mediana & 10,4 & 9,5 & 19,0 & 7,2 & 7,0 & 3,2 & 8,0 \\
Variância & 01,6 & 0,2 & 01,7 & 0,9 & 0,8 & 0,1 & 3,0 \\
Desvio padrão & 03,8 & 0,6 & 06,9 & 0,4 & 3,1 & 0,3 & 2,0 \\
Amplitude & $12,2-6,5$ & $10,5-7,8$ & $21,8-12,0$ & $9,9-6,0$ & $8,8-4,4$ & $4,1-2,1$ & $15,0-2,0$ \\
\hline CV (\%) & 37,1 & 5,9 & 36,5 & 5,8 & 44,6 & 10,4 & 28,9 \\
\hline
\end{tabular}

Fonte: Elaboração dos autores.

As sementes são oblongas-ovaladas, com base superior mais larga que a inferior (Figura 3A), apresentando, quando maduras, coloração marrom, um pouco mais claro que o fruto. O halo apresenta-se marrom escuro, com micrópila e hilo visíveis, que por sua vez, apresentam coloração branca. Possui, em média, 9,6 $\mathrm{mm}$ de comprimento por 7,2 $\mathrm{mm}$ de largura e 3,2 $\mathrm{mm}$ de espessura, com pequena variação nessas dimensões (Tabela 1), observando-se deslocamento assimétrico positivo para a frequência de comprimento (Figura 2B), ou seja, o valor modal localiza-se à esquerda dos valores mediano e médio $\left(\mathrm{m}_{0}<\mathrm{md}<\mathrm{m}\right)$ e distribuição simétrica para as frequências de largura e espessura $(\mathrm{mo}=\mathrm{md}=\mathrm{m})$ (Figura $2 \mathrm{D}$ e F). 
Figura 2. Distribuição da frequência relativa (Fr) do comprimento, largura e espessura de frutos (A, C, E) e sementes (B, D, F) de Caesalpinia pulcherrima (L.) Sw.
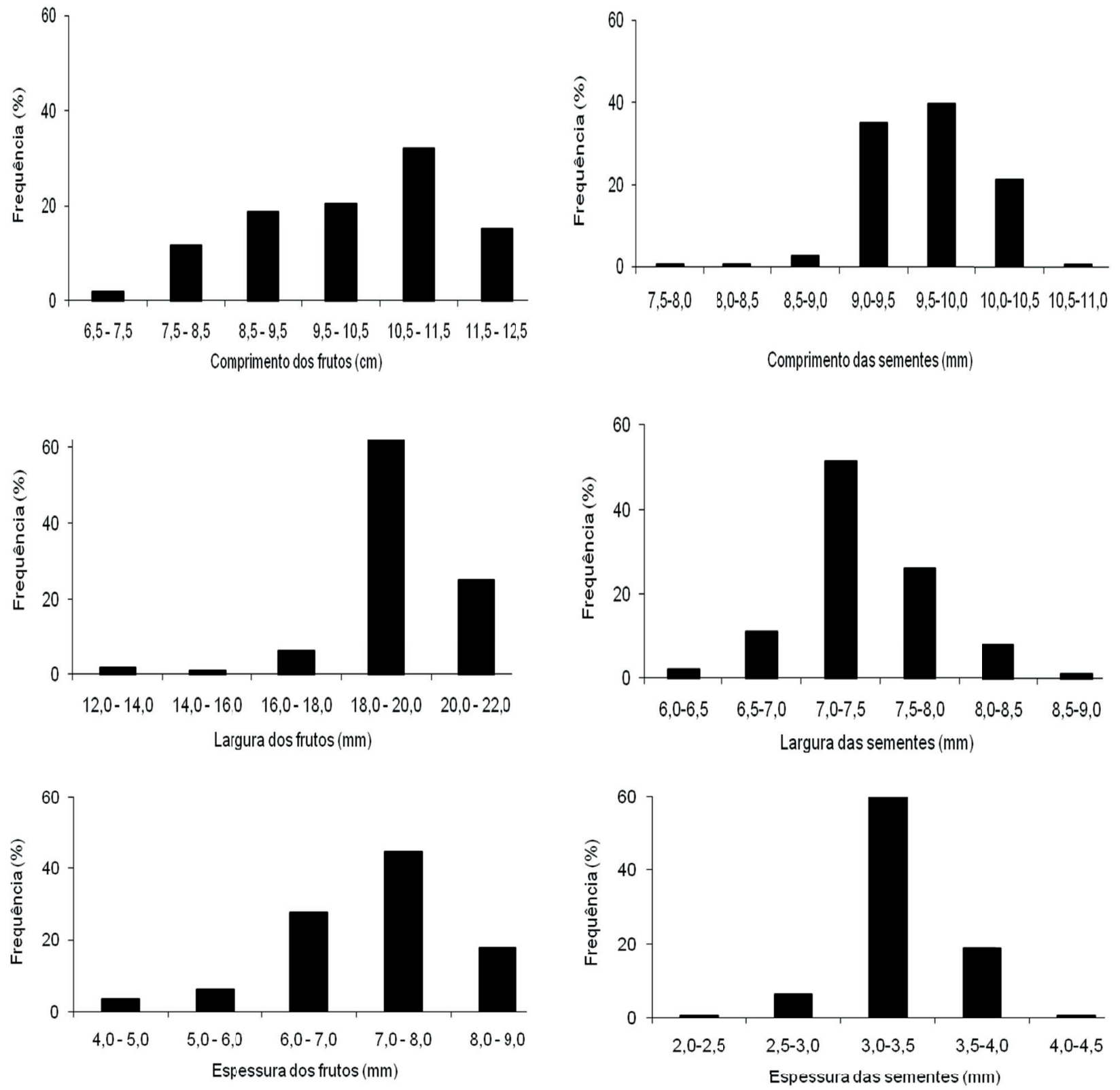

Fonte: Elaboração dos autores.

O embrião é do tipo axial-linear, com eixohipocótilo radícula cilíndrico, coloração creme, diferenciadas (Figura 3B). Os cotilédones são com porção superior formada de plúmulas bem carnosos, isófilos e oblongos convexos. 
Figura 3. Estruturas externas e internas de sementes de Caesalpinia pulcherrima (L.) Sw.
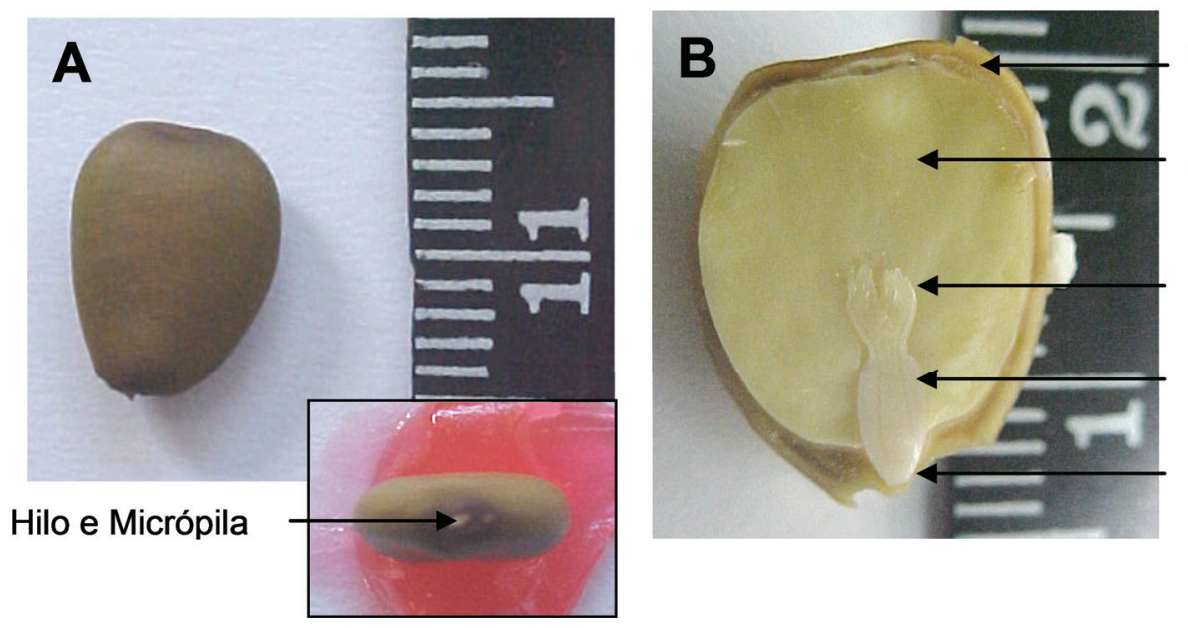

Tegumento

Cotilédone

Plúmula

Hipocótilo-radícula

Fonte: Elaboração dos autores.

A escarificação mecânica do tegumento foi eficiente na superação da dormência proporcionando maior porcentagem de germinação, independentemente da temperatura testada (Tabela 2). Este mesmo tratamento proporcionou também maior velocidade de germinação (IVG) sendo superior quando as sementes foram incubadas a temperatura constante de $30^{\circ} \mathrm{C}$. Tais resultados corroboram os encontrados por Gilman, Watson (2003) e Oliveira et al. (2010) que observaram a presença de dormência do tipo tegumentar nas sementes dessa espécie. Estes últimos autores observaram que a germinação dessas sementes em condições não controladas foi acelerada após serem escarificadas com lixa de n. 80 seguida de embebição das sementes em água por 12 e 24 horas, sob temperatura constante de $30^{\circ} \mathrm{C}$. Por outro lado, Navarrete-Tindall (2002) descrevendo a biologia dessa espécie, relata que as suas sementes não necessitam de tratamentos pré-germinativos e que sementes intactas, recém-colhidas, atingem de 90 a $100 \%$ de germinação.

Tabela 2. Porcentagem (G\%) e velocidade de germinação (IVG) de sementes de Caesalpinia pulcherrima (L.) Sw. submetidas à diferentes tratamentos para superação da dormência.

\begin{tabular}{lcc}
\hline \multicolumn{1}{c}{ Tratamentos } & G (\%) & IVG \\
\hline Testemunha (sementes intactas) & $60,63 \mathrm{~B}$ & $5,1 \mathrm{~B}$ \\
Escarificação mecânica & $70,47 \mathrm{~A}$ & $6,9 \mathrm{~A}$ \\
Imersão em água à temperatura ambiente & $47,93 \mathrm{C}$ & $1,49 \mathrm{C}$ \\
\hline \multicolumn{2}{c}{ Temperaturas } & \\
\hline $25^{\circ} \mathrm{C}$ & $58,89 \mathrm{~A}$ & $4,5 \mathrm{~B}$ \\
$30^{\circ} \mathrm{C}$ & $60,46 \mathrm{~A}$ & $5,3 \mathrm{~A}$ \\
\hline Valor de "F" para tratamento de dormência (D) & $28,65^{* *}$ & $92,07^{* *}$ \\
Valor de "F" para Temperatura (T) & $0,42^{\text {ns }}$ & $9,0^{* *}$ \\
Valor de "F" para interação (D x T) & $1,74^{\text {ns }}$ & $1,0^{\text {ns }}$ \\
$C V(\%)$ & 10,01 & 12,6 \\
\hline
\end{tabular}

Médias seguidas de mesma letra na coluna não diferem entre si pelo teste de Tukey a 5\% de probabilidade de erro.

Fonte: Elaboração dos autores. 
A escarificação mecânica é um método abrasivo que requer cuidados durante o manuseio, para evitar danos ao embrião. Apesar disso, é um dos procedimentos mais utilizados em sementes impermeáveis à água, com eficiência relatada para aquelas que apresentam potencial ornamental, destacando-se as espécies da família Fabaceae, Dinizia excelsa Ducke (MEDEIROS FILHO; SILVA; SANTOS FILHA, 2005), Acacia caven (Mol.) Mol. (ESCOBAR et al., 2010) e Peltophorum dubium (Spreng.) Taub. (PIROLI et al., 2005).

O tratamento de imersão das sementes em água destilada por 24 horas à temperatura ambiente proporcionou os mais baixos valores para porcentagem e velocidade de germinação, indicando a baixa eficiência deste método na superação da dormência dessas sementes (Tabela 2). Tal ineficiência também foi observada em sementes de Senna machranthera Collad (Fabaceae) (FERREIRA; PEREZ, 1997) e de Parkia pendula Benth. (Fabaceae) (BARBOSA; VASTANO; VARELA, 1984). Estes últimos autores comentaram que os baixos valores de germinação podem ter sido causados pela deficiência no suprimento de oxigênio para o embrião resultante do prolongado período de imersão em água, que de certa forma, explica os baixos valores de porcentagem de germinação quando comparado com o tratamento para o qual as sementes permaneceram intactas.

Valores relativamente elevados de germinação em sementes intactas de $C$. pulcherrima foram também observados por Oliveira et al. (2010). Esse comportamento sugere que uma parcela das sementes dessa espécie apresentaria dormência, permanecendo no banco de sementes. Essa distribuição da intensidade ou profundidade de dormência, do ponto de vista ecológico é de grande importância, pois permite a uma determinada espécie, produzir sementes em determinada época e as mesmas permanecerem viáveis por vários meses e/ou anos contribuindo para a sua disseminação. Tal característica pode fazer parte da estratégia de estabelecimento da espécie, garantindo a germinação das sementes ao longo do tempo.

Aproximadamente $40 \%$ das sementes intactas de C. pulcherrima não germinaram, indicando que, sob condições, naturais fariam parte do banco de sementes do solo. Provavelmente essa espécie apresenta distribuição da germinação no tempo, obtida pela indução de dormência nas sementes, que por sua vez, pode variar em intensidade (CARVALHO; NAKAGAWA, 2000), sendo este um dos principais mecanismos de preservação de espécies em bancos de sementes (CARMONA, 1995). Sob condições naturais, essa característica pode garantir a sobrevivência da espécie, na condição de semente, em situações adversas, mesmo quando a vegetação é completamente eliminada. Boa parte das espécies silvestres geralmente apresentam mecanismos de dormência, enquanto as cultivadas mais comuns foram perdendo este mecanismo por processo de seleção durante a domesticação, resultando nas variedades modernas com pouca ou nenhuma dormência (CARMONA, 1992).

Quando as sementes foram escarificadas mecanicamente, a porcentagem de germinação foi relativamente elevada e crescente entre as temperaturas de $15^{\circ} \mathrm{C}$ a $40^{\circ} \mathrm{C}$ (Figura 4). Por outro lado, O IVG foi crescente com o aumento da temperatura, até $31,2^{\circ} \mathrm{C}$ (temperatura estimada pelo ponto de máxima da curva), decrescendo a partir dai. Com relação às sementes intactas, constatouse que a porcentagem de germinação foi baixa à temperatura de $15^{\circ} \mathrm{C}$ e aumentou até à temperatura de $33,2{ }^{\circ} \mathrm{C}$ (valor obtido pela estimativa do ponto de máxima da curva), decrescendo a partir daí. A temperatura estimada que otimizou o IVG das sementes intactas foi de $32^{\circ} \mathrm{C}$. Nestas condições, as sementes não germinadas à temperatura de $15^{\circ} \mathrm{C}$ permaneceram com aspecto sadio durante o período de observação. Isso mostra que temperaturas mais baixas afetam a absorção de água, provavelmente pela interação da maior viscosidade do líquido com a rigidez das membranas (MURPHY; NOLAND, 1982). 
Figura 4. Porcentagem (G\%) e velocidade de germinação (IVG) de sementes de Caesalpinia pulcherrima (L.) Sw. escarificadas mecanicamente e intactas em função de diferentes temperaturas.
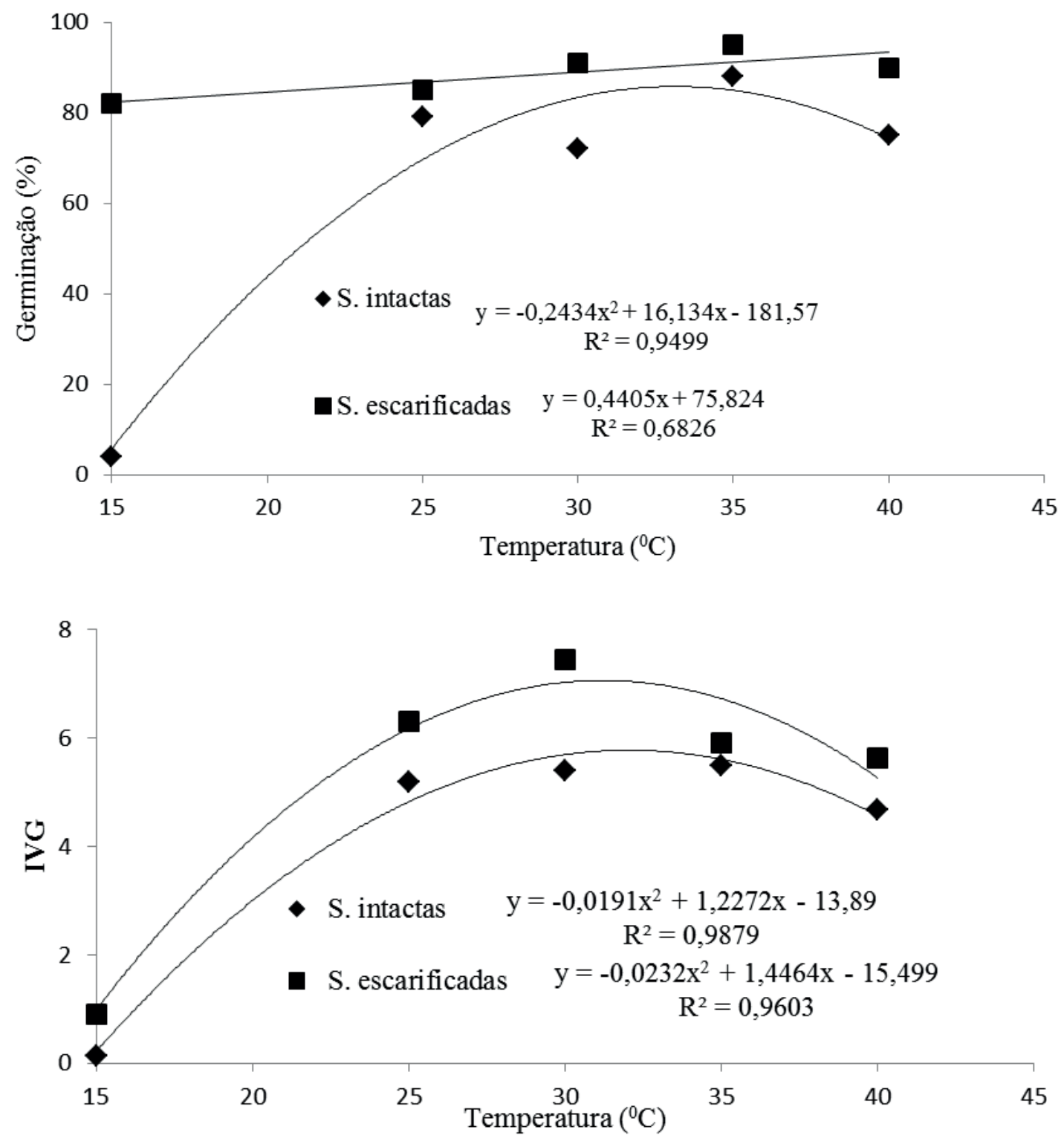

Fonte: Elaboração dos autores.

Tanto para as sementes intactas quanto para as escarificadas, observou-se que a temperatura de $45^{\circ} \mathrm{C}$ inibiu completamente a germinação das sementes (dados não apresentados). Além disso, as sementes submetidas a essa temperatura apresentaram, em poucos dias, aspecto deteriorado, indicado pela consistência amolecida e odor desagradável.

A germinação das sementes pode ocorrer sob limites relativamente amplos de temperatura
(MARCOS FILHO, 2005), cujos extremos dependem principalmente da espécie e suas características genéticas e das condições do ambiente durante a produção. Assim, considerando o conceito de que a temperatura ótima seria aquela na qual há combinação mais eficiente entre a porcentagem e a velocidade de germinação, pode-se inferir que para a espécie estudada a temperatura de $30^{\circ} \mathrm{C}$ apresenta-se como ótima 
para a germinação das sementes. Tais resultados confirmam os encontrados por Oliveira et al. (2012) e Camara et al. (2008) em sementes das Fabáceas Anadenanthera macrocarpa (Benth.) Brenan e Parkia pendula (Willd.) Benth. ex Walp., respectivamente, nos quais os autores observaram que o uso de temperaturas extremas (acima de $40^{\circ} \mathrm{C}$ ) causaram a deterioração das sementes, evidenciadas também pelo aspecto mole e odor desagradável. Para Garcia et al. (2004) tais temperaturas podem provocar desorganização do sistema enzimático, com desnaturação de proteínas e desestruturação do sistema de membranas celulares, comprometendo a germinação das sementes.
Com relação às respostas fisiológicas das sementes em função da dessecação, constatouse que a germinação foi mantida com até 120 horas de secagem, o que correspondeu a um grau de umidade de 3,7\% (Tabela 3). No entanto, a qualidade fisiológica foi prejudicada, reduzindo o IVG, com 48 horas ou mais de secagem, enquanto que a quantidade de lixiviados aumentou significativamente a partir de 72 horas, nestes períodos o grau de umidade das sementes atingiu 4,9 e $4,6 \%$ de umidade, respectivamente. Tal resposta indica que as sementes em estudo podem ser consideradas ortodoxas, no entanto, não devem ser armazenadas com grau de umidade abaixo de 5\%, conforme sugerido por Roberts (1973).-

Tabela 3. Grau de umidade (\%), porcentagem de germinação (G\%), índice de velocidade de germinação (IVG) e condutividade elétrica (CE) de sementes de Caesalpinia pulcherrima (L.) Sw. submetidas à diferentes períodos de secagem.

\begin{tabular}{ccccc}
\hline $\begin{array}{c}\text { Período de secagem } \\
\text { horas }\end{array}$ & Grau de umidade (\%) & Germinação (\%) & IVG & $\begin{array}{c}\text { C.E } \\
\mu \mathrm{mhos} \mathrm{cm}^{-1} \mathrm{~g}^{-1}\end{array}$ \\
\hline 0 & 7,0 & $94,6 \mathrm{~A}$ & $7,3 \mathrm{~A}$ & $68,51 \mathrm{C}$ \\
24 & 5,1 & $98,0 \mathrm{~A}$ & $6,1 \mathrm{AB}$ & $69,79 \mathrm{BC}$ \\
48 & 4,9 & $99,0 \mathrm{~A}$ & $5,4 \mathrm{~B}$ & $70,53 \mathrm{BC}$ \\
72 & 4,6 & $96,0 \mathrm{~A}$ & $5,8 \mathrm{~B}$ & $76,49 \mathrm{AB}$ \\
120 & 3,7 & $98,0 \mathrm{~A}$ & $4,9 \mathrm{~B}$ & $75,94 \mathrm{AB}$ \\
168 & 2,8 & $88,0 \mathrm{~B}$ & $5,3 \mathrm{~B}$ & $77,80 \mathrm{~A}$ \\
\hline $\mathrm{CV}(\%)$ & & 9,0 & 6,9 & 3,58 \\
\hline
\end{tabular}

Médias seguidas de mesma letra na coluna não diferem entre si pelo teste de Tukey a 5\% de probabilidade de erro.

Fonte: Elaboração dos autores.

Constatou-se que a qualidade fisiológica das sementes armazenadas com grau de umidade inicial de $7 \%$ foi mantida em todos os períodos de estocagem estudados, independente da embalagem e ambiente (Figura 5 A, B, C e D), assim como houve estabilidade do teor de água das sementes durante este período, sendo observada pequena alteração do conteúdo de água durante os 270 dias de armazenamento (Figura 5 E e F), indicando eficiência na manutenção da umidade e, consequentemente, confiabilidade nas comparações realizadas neste processo. Resultados contrários foram observados por Lacerda et al. (2002) com sementes de Caesalpinia ferrea Mart.(Fabaceae), onde o declínio da qualidade fisiológica das sementes armazenadas em câmara seca foi atribuído ao grau de umidade das mesmas que passou de $8 \%$ do início do armazenamento para $14 \%$, sendo recomendado pelos autores o uso de embalagens impermeáveis nestas condições. 
Figura 5. Porcentagem de germinação (G\%), índice de velocidade de germinação (IVG) e grau de umidade de sementes de Caesalpinia pulcherrima (L.) Sw. armazenadas sob condições não controladas (A, C, E) e controladas (B, D, F) de temperatura e umidade.
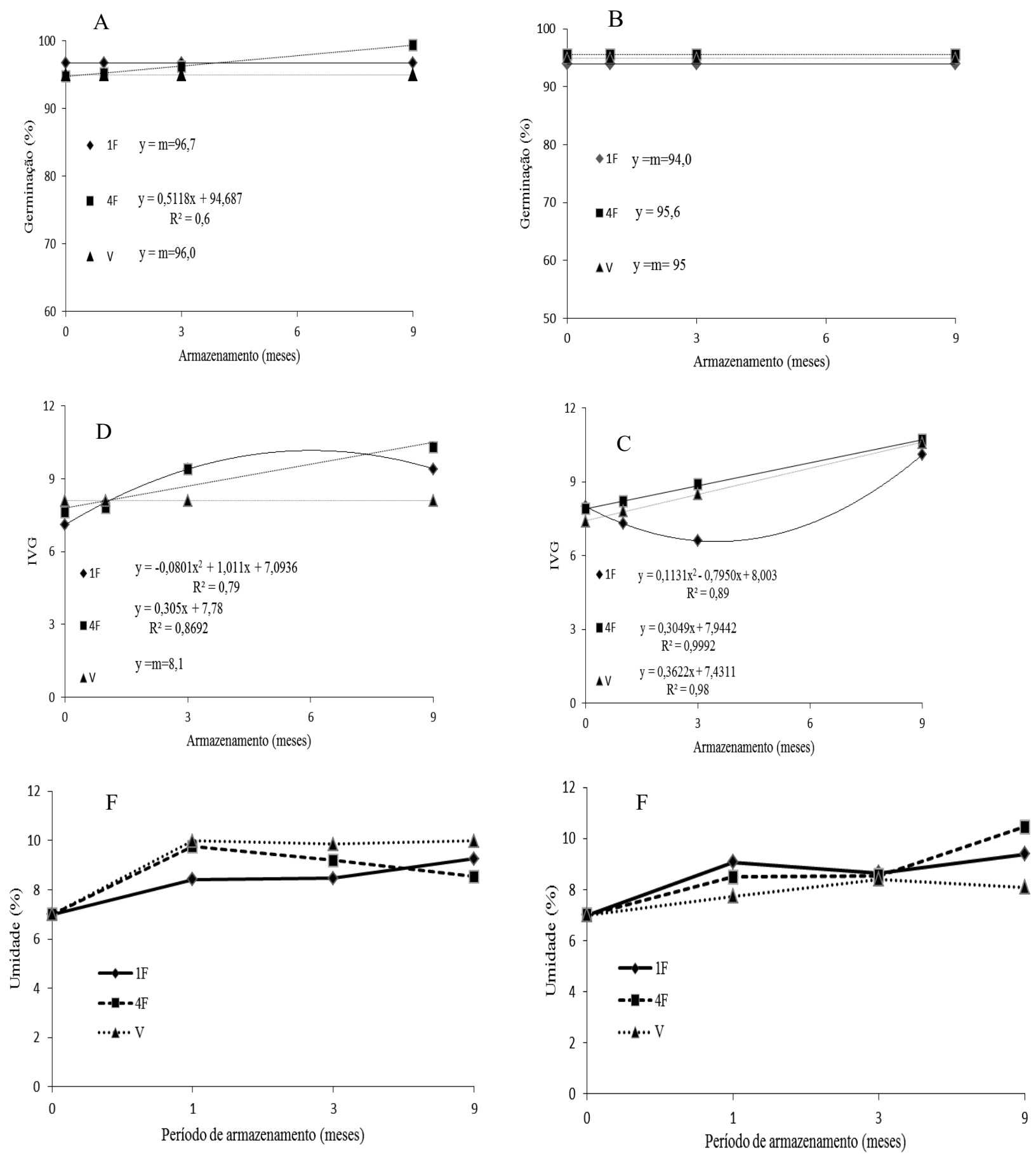

Fonte: Elaboração dos autores. 


\section{Conclusões}

O fruto de Caesalpinia pulcherrima é do tipo legume, deiscente, polispérmico, apresentando em média sete sementes, que apresentam formato oblongo-ovalado. O embrião é do tipo axial linear com eixo hipocótilo-radícula reto.

A máxima germinabilidade é obtida em sementes incubadas a $30^{\circ} \mathrm{C}$, após escarificação mecânica realizada no lado oposto à micrópila.

A qualidade fisiológica das sementes foi mantida por 270 dias, quando armazenadas com grau de umidade de $7 \%$, independente da embalagem e condições de armazenamento.

\section{Referências}

ALVINO, F. O.; RAYOL, B. P.; SILVA NETO, P. A.; MUNIZ, A. L. V.; RIBEIRO, M. S. Armazenamento e germinação de sementes de Sclerolobium paniculatum vogel (Leguminosae-Caesalpinioideae). Revista Brasileira de Biociências, Porto Alegre, v. 5, p. 726-728, 2007. Suplemento 2.

BANZATTO, D. A.; KRONKA, S. N. Experimentação agrícola. 2. ed. Jaboticabal: FUNEP, 1992. 246 p.

BARBEDO, C. J.; BILIA, D. A. C., RIBEIRO, R. C. L. F. Tolerância à dessecação e armazenamento de sementes de Caesalpinia echinata Lam. (pau-brasil), espécie da Mata Atlântica. Revista Brasileira de Botânica, São Paulo, v. 25, n. 4, p. 431-439, 2002.

BARBOSA, A. P.; VASTANO, B.; VARELA, V. P. Tratamentos pré-germinativos de sementes de espécies florestais amazônicas. II - visgueiro (Parkia pendula Benth. Leguminosae-Mimosoideae). Acta Amazonica, Manaus, v. 14, n. 1-2, p. 280-288, 1984.

BASKIN, C. C.; BASKIN, J. M. Seeds: ecology, biogeography, and evolution of dormancy and germination. London: Academic Press, 1998. 668 p.

BRASIL. Ministério da Agricultura, Pecuária e Abastecimento. Regras para análise de sementes. Ministério da Agricultura, Pecuária e Abastecimento. Secretaria de Defesa Agropecuária. Brasília, DF: Mapa/ ACS, 2009. $395 \mathrm{p}$.

CALIL, A. C.; LEONHARDT, C.; SOUZA, L. S. S.; SILVA, V. S. Influência do armazenamento em câmara fria sobre a viabilidade de sementes de Calliandra foliolosa Benth. (Leguminosae-Mimosoideae). Revista
Brasileira de Biociências, Porto Alegre, v. 5, p. 774-776, 2007. Suplemento 1.

CAMARA, C. A; ARAÚJO NETO, J. C; FERREIRA, V. M.; ALVES, E. U.; MOURA, F. B. P. Caracterização morfométrica de frutos e sementes e efeito da temperatura na germinacão de Parkia pendula (Willd.) Benth. ex Walp. Ciência Florestal, Santa Maria, v. 18, n. 3, p. 281290, 2008.

CARMONA, R. Banco de sementes e estabelecimento de plantas daninhas em agroecossistemas. Planta Daninha, Viçosa, v. 13, n. 1, p. 3-9, 1995.

CARMONA, R. Problemática e manejo de bancos de sementes de invasoras em solos agrícolas. Planta Daninha, Viçosa, v. 10, n. 1-2, p. 5-16, 1992.

CARVALHO, N. M.; NAKAGAWA, J. Sementes: ciência, tecnologia e produção. 4. ed. Jaboticabal: Funep, 2000. 588 p.

CÓRNER, E. J. H. The seeds of dicotyledons. Cambridge: University Press, 1976. v. 1, 311 p.

ELLIS, R. H.; HONG, T. D.; ROBERTS, H. An intermediate category of seed storage behaviour? I. Coffee. Journal of Experimental of Botany, Oxford, v. 41, n. 230, p. 1167-1174, 1990.

ESCOBAR, T. A.; PEDROSO, V. M.; BONOW, R. N.; BONOW, R. N.; SCHWENGBERS, E. B. Superação de dormência e temperaturas para germinação de sementes de Acacia caven (Mol.) Mol. (ESPINILHO). Revista Brasileira de Sementes, Porto Alegre, v. 32, n. 2, p. 124130, 2010.

FERREIRA, M. S. E.; PEREZ, S. C. J. G. A. Tratamentos para superar a dormência de sementes de Senna macranthera (Collad.) Irwin et Barn. (FabaceaeCaesalpinoideae). Revista Brasileira de Sementes, Porto Alegre, v. 19, n. 2, p. 230-236, 1997.

GARCIA, D. C.; BARROS A. C. S. A.; PESKE, S. T.; MENEZES, N. L. A secagem de sementes. Ciência Rural, Santa Maria, v. 34, n. 2, p. 603-608, 2004.

GIACHINI, R. M.; LOBO, F. A.; ALBUQUERQUE, M. C. F.; ORTIZ, C. E. R. Influência da escarificação e da temperatura sobre a germinação de sementes de Samanea tubulosa (Benth.) Barneby \& J.W. Grimes (sete cascas). Acta Amazônica, Manaus, v. 40, n. 1, p. 75-80, 2010.

GILMAN, E. F.; WATSON, D. G. Caesalpinia pulcherrima Dwarf Poinciana. USDA Forest Service Fact Sheet ST-107, 2003. 3 p. Disponível em: <http:// www.edis.ifas.ufl.edu/pdffiles/ST/ST10700.pdf $>$. Acesso em: 18 out. 2013.

HONG, T. D.; ELLIS, R. H. A protocol to determine seed storage behaviour. Rome: International Plant Genetic 
Resources Institute, 1996. 55 p. (IPGRI. Technical Bulletin, 1).

JACOMINE, P. K. T.; CAVALCANTI, A. C.; PESSOA, S. C. C.; SILVEIRA, C. O. Levantamento exploratórioreconhecimento de solos do Estado de Alagoas. Recife: EMBRAPA, Centro de Pesquisas Pedológicas, 1975. 532 p. (Boletim técnico, 35).

LABOURIAU, L. G.; VALADARES, M. B. On the physiology of seed of Calotropis procera. Anais da Academia Brasileira de Ciência, Rio de Janeiro, v. 42, n. 2, p. 235-264, 1976.

LACERDA, S. N. B.; MARIO, E. R. M.; CAVALCANTI, M.; BRAGA, M. E. D.; SILVA, F. A. S. Estudo comparativo da crioarmazenagem de semente de pau-ferro (Caesalpinia ferrea Mart.) com as técnicas convencionais de armazenagem. Revista Brasileira de Produtos Agroindustriais, Campina Grande, v. 4, n. 1, p. 7-14, 2002.

LOPES, J. C.; BARBOSA, L. G.; CAPUCHO, M. T. Germinação de sementes de Bauhinia spp. Floresta, Curitiba, v. 37, n. 2, p. 265-274, 2007.

LORENZI, H.; SOUZA, H. M. Plantas ornamentais no Brasil: arbustivas, herbáceas e trepadeiras. Nova Odesa: Plantarum, 2008. 1088 p.

MARCOS FILHO, J. Fisiologia de sementes de plantas cultivadas. Piracicaba: FEALQ, 2005. 495 p.

MEDEIROS FILHO, S.; SILVA, M. A. P.; SANTOS FILHA, M. E. C. Germinação de sementes e desenvolvimento de plântulas de Caesalpinia ferrea Mart. ex Tul var. ferrea em casa de vegetação e germinador. Revista Ciência Agronômica, Fortaleza, v. 36, n. 2, p. 203-208, 2005.

MURPHY, J. B.; NOLAND, T. L. Temperature effects on seed imbibition and leakage mediated by viscosity and membranes. Plant Physiology, Maryland, v. 69, n. 2, p. 428 431, 1982.

NAVARRETE-TINDALL, N. Caesalpinia Pulcherrima (L.) Sw. In: VOZZO, J. A. Tropical tree seed manual. Washington DC: United States Department of Agriculture. Forest Service, 2002. 899 p.
NAZARIO, P.; FERREIRA, S. A. N.; REBOUÇAS, E. R. Germinação de sementes de Cynometra bauhiniifolia Benthan (jutairana) em função do dessecamento e da manutenção sob condição úmida. Acta Amazonica, Manaus, v. 38, n. 3, p. 439-444, 2008.

OLIVEIRA, A. K. M.; SCHLEDER, E. D.; FAVERO, O. Caracterização morfológica, viabilidade e vigor de sementes de Tabebuia aurea (silva manso) Benth. \& Hook. f. ex. S. Moore. Revista Árvore, Viçosa, v. 30, n. 1, p. 25-32, 2006.

OLIVEIRA, L. M.; BRUNO, R. L. A.; GONÇALVES, E. P.; LIMA JÚNIOR, A. R. Tratamentos pré-germinativos em sementes de Cesalpinia pulcherrima (L.) Sw. Leguminosae. Revista Caatinga, Mossoró, v. 23, n. 1, p. 71-76, 2010.

OLIVEIRA, L. M.; DAVIDE, A. C.; CARVALHO, M. L. M. Teste de germinação de sementes de Peltophorum dubium (SPRENGl) TAUBERT-Fabaceae. Floresta, Curitiba, v. 38, n. 3, p. 545-551, 2008.

OLIVEIRA, S. S. C.; ARAUJO NETO, J. C.; CRUZ, S. J. S.; FERREIRA, V. M. Caracterização morfométrica de sementes e plântulas e germinação de Anadenanthera macrocarpa (Benth.) Benan. Ciência Florestal, Santa Maria, v. 22, n. 3, p. 643-653, 2012.

PEREZ, S. C. J. C. A. Envoltórios. In: FERREIRA, A. G.; BORGHETTI, F. (Org.). Germinação: do básico ao aplicado. Porto Alegre: ARTMED, 2004. p. 125-134.

PIROLI, E. L.; CUSTÓDIO, C. C.; ROCHA, M. R. V.; UDENAL, J. L. Germinação de sementes de canafístula (Peltophorum dubium (Spreng.) Taub.) tratadas para superação da dormência. Colloquium Agraria, Presidente Prudente, v. 1, n. 1, p. 13-18, 2005.

ROBERTS, E. H. Predicting the storage life of seeds. Seed Science and Technology, Zurich, v. 1, n. 3, p.499514, 1973.

ROLSTON, M. P. Water impermeable seed dormancy. The Botanical Review, Athens, v. 44, n. 3, p. 365-396, 1978. 
